\title{
LA CUEVA DE MADRID. MAGIAY TRAMOYA EN LA DAMA DUENDE
}

\author{
Wolfram Nitsch \\ Universität zu Köln \\ Romanisches Seminar \\ Albertus Magnus Platz \\ 50923 Köln \\ Alemania \\ wolfram.nitsch@uni-koeln.de
}

REFLEXIONES SOBRE LA MAGIA: ENTRE TÉCNICA Y RETÓRICA

Según las investigaciones de la antropología cultural y social, la magia tiene mucho parecido con la técnica y con la retórica. Como las artes mecánicas, trata de dominar a la naturaleza; y como la oratoria, intenta manipular la conducta humana ${ }^{1}$. Con respecto al primer aspecto, la magia se presenta como un equivalente arcaico de la técnica y de la ciencia aplicada. Esto ya lo subraya, desde un punto de vista crítico, James Frazer, uno de los precursores de la antropología moderna. Las dos variantes de la magia distinguidas por él se basan en una aplicación errónea de las dos leyes de la asociación psíquica. La magia imitativa, practicada cuando se hiere al retrato de una persona a fin de

\footnotetext{
${ }^{1}$ Ver el informe muy conciso de Tambiah, 1990, pp. 42-83.
} 
herir a ella misma, presupone que la ley de la semejanza, vigente en la mente humana, vale también para la naturaleza entera; y la magia de contacto, ejecutada por el que trata de envenenar a alguien envenenando su ropa dejada atrás, comete el mismo error con respecto a la ley de la contigüidad. Por eso, para Frazer la magia no es más que una «hermana bastarda» de la ciencia y al mismo tiempo una enemiga peligrosa de la religión, ya que el mago reclama para sí mismo el poder que el sacerdote atribuye a los seres divinos ${ }^{2}$. Frente a tales reservas, varios sucesores del antropólogo inglés han rehabilitado la magia, considerándola como un complemento necesario de la técnica. Según Malinowski, por ejemplo, el acto mágico solamente se sustituye al acto mecánico en situaciones incalculables que revelan los límites del dominio técnico de la naturaleza ${ }^{3}$.Y Marcel Mauss ve en la magia hasta un «arte de hacer» por excelencia, un conjunto de operaciones prácticas cuya «eficacia real» anima a las sociedades arcaicas a lanzarse en la experimentación técnica ${ }^{4}$.

Empero, una tal eficacia real sólo se deja atribuir al acto mágico si éste se concibe como un acto de persuasión retórica. En esta perspectiva, la antropología moderna subraya el carácter performativo de la magia, corroborando con datos empíricos el argumento fundamental que ya Wittgenstein oponía a la teoría de Frazer. Según el filósofo vienés, el mago no puede errar porque cumple un acto ritual con efectos reales: «In effigie verbrennen. Das Bild des Geliebten küssen [...] bezweckt eine Befriedigung und erreicht sie auch» («El abrasar en efigie, el besar la imagen del amante [...] persigue una satisfacción y termina por lograrla») ${ }^{5}$. Esto lo confirman en particular los estudios de campo realizados por Malinowski que además de la función casi técnica de la magia demuestran su fuerza performativa. Mediante un conjuro acompañado por un juego de rol expresivo, el mago crea una nueva situación ratifica-

${ }^{2}$ Ver Frazer, 1911, pp. 52-243, en particular p. 222. Una descripción detallada y frecuentemente imitada de las variantes de la magia se halla en las Bucólicas de Virgilio donde una mujer abandonada por su marido lo obliga a regresar tras manipular tanto su retrato como su vestido (VIII, vv. 64-109).

${ }^{3}$ Ver Malinowski, 1974, pp. 25-36 y 85-87, con respecto a la distinción que hacen los trobriandeses entre la pesca puramente técnica en las lagunas y la pesca de alta mar, acompañada por actos mágicos.

${ }^{4}$ Ver Mauss y Hubert, 1985, pp. 134-135.

${ }^{5}$ Wittgenstein, 1989 , p. 32 (mi traducción). 
da por la comunidad ${ }^{6}$. Como lo documentan algunos casos estudiados por Mauss y su discípulo Lévi-Strauss, incluso un mago bastante escéptico (y, por lo tanto, algo cínico) puede sucumbir a su propia actuación si el público se deja persuadir: «le magicien se dupe lui-même, comme l'acteur qui oublie qu'il joue un rôle» ${ }^{7}$. De tal modo, la magia alcanza como una manipulación casi retórica o teatral de la sociedad lo que aún no consigue como una manipulación técnica de la naturaleza.

Me parece que estas observaciones generales, propuestas acerca de culturas indígenas lejanas, merecen también atención con respecto a la reflexión sobre la magia en el Siglo de Oro ${ }^{8}$. Si a finales del siglo XVI el jesuita Martín del Río distingue tres formas principales de la magia, la magia naturalis, la magia diabolica y la magia artificiosa, esta clasificación se basa por su parte en una ponderación cada vez diferente del aspecto técnico y del aspecto retórico que le son inherentes ${ }^{9}$. En el caso de la magia natural prevalece el dominio casi técnico de la naturaleza. Esto se puede ver ante todo en De magia de Giordano Bruno y en otros tratados del renacimiento italiano donde la valoración neoplatónica de la magia favorece el desarrollo de la técnica moderna ${ }^{10}$. Los manuales correspondientes del renacimiento español, en cambio, no prestan tanta atención a la magia natural, aunque le concedan cierta legitimidad. Hasta un libro tan severo como la Reprobación de las supersticiones y hechicerías del maestro Pedro Ciruelo incluye un excurso sobre «remedios naturales» que permiten intervenir en el cuerpo humano ${ }^{11}$.

En primer lugar, sin embargo, los tratados españoles se dedican a la magia diabólica que describen como una manipulación aparentemente técnica de la naturaleza, pero secretamente basada en una manipulación retórica del mismo mago por el demonio. Ciruelo y sus sucesores, en particular Antonio de Torquemada, no ponen en duda la eficacia real de esta magia que a lo sumo puede mover montañas; no obstante, niegan el poder del mago, porque actúa como un mero ayudante de Satanás:

${ }^{6}$ Ver por ejemplo Malinowski, 1974, pp. 69-90; acerca de la afinidad patente entre su teoría de la magia y la teoría de los actos de habla propuesta por Austin, ver Todorov, 1973, pp. 39-40.

${ }^{7}$ Ver Mauss y Hubert, 1985, pp. 86-89. Para el caso de un chamán kwakiutl que se inició a su oficio simulando actos mágicos, véase Lévi-Strauss, 1974, pp. 200-209.

${ }^{8}$ Sobre el contexto europeo de esta reflexión, ver Grafton, 2002.

${ }^{9}$ Del Río, 1599/1600, vol. 1, p. 13.

${ }^{10}$ Ver Yates, 1964, pp. 144-156.

${ }^{11}$ Ciruelo, 1952, pp. 99-102. 
«si viene a efecto es por secreta operación del diablo» ${ }^{12}$. Tanto la omnipotencia del encantador como la omniciencia que afirma en sus adivinaciones es un artificio engañoso del diablo que por su parte no actúa sino por orden de Dios, como el instrumento ciego de un examen o de un castigo divino. La intervención secreta del diablo se manifiesta en el caso del nigromante quien firma un pacto explícito con el demonio y se equivoca solamente con respecto a su presumida superioridad, ya que si puede conjurar al consejero infernal, no puede encerrarlo ni dirigirlo: «los nigrománticos por sí, ni por sus palabras, o caracteres, o signos, no son poderosos para hacer que un demonio les obedezca, ni haga cosa ninguna por su voluntad, aunque ellos piensan lo contrario a esto» ${ }^{13}$. Aún más se equivocan los magos que creen producir efectos sobrenaturales sin conjuración previa del demonio. Lo que piensan lograr por magia natural resulta en realidad de la magia del diablo que sabe disimular su propia intervención con mucha destreza, «mezclando lo uno con lo otro, que son la mágica natural con lo del demonio» ${ }^{14}$. En breve, la magia diabolica es caracterizada en los tratados españoles como un acto seudo-técnico que no prueba el poder del mago sobre la naturaleza, sino al contrario la persuasión retórica de éste por las fuerzas del mal.

Una relación distinta entre técnica y retórica marca la magia artificio$s a$. En esta tercera variante más reciente de la magia, conocida solamente desde el siglo XVI, el mismo mago vincula el acto técnico a un acto retórico, dado que finge efectos sobrenaturales con medios sumamente materiales. Mientras que en las prácticas de la magia diabólica sucumbe al engaño del mirabilis artifex Satanás, en este caso crea un artificio no menos engañoso con sus propias manos. Las reflexiones expresas sobre la magia artificiosa se refieren de preferencia a ciertas técnicas de ilusión óptica como las anamorfosis, los aparatos catóptricos o los trucos del prestidigitador ${ }^{15}$. Empero, esta forma de la magia incluye también los medios de la ilusión teatral. No en balde se habla de una propia magia

12 Ciruelo, 1952, p. 28. Resulta tanto más fácil interpretar tales «efectos maravillosos» como obras del diablo que el mundo cristianizado escasean los milagros divinos (Ciruelo, 1952, p. 72). También Antonio de Torquemada opina que el demonio puede mover montañas; ver Torquemada, 1982, p. 257.

${ }^{13}$ Torquemada, 1982, p. 288.

${ }^{14}$ Ver Torquemada, 1982, pp. 305-306. Torquemada apoda «hechiceros» a tales magos que no firman un pacto con el diablo, a diferencia de los «encantadores» entre los cuales figuran los «nigromantes» y los «brujos».

${ }^{15}$ Ver Kemp, 1990, pp. 205-217; García Santo-Tomás, 2014, pp. 157-188. 
del teatro que resulta por su parte de una colaboración sugestiva entre técnica y retórica, ya que al arte oratorio e histriónico del actor se junta la maquinaria del escenario. Sin embargo, de esta variante quizás más poderosa de la magia artificiosa no se dice mucho en los tratados correspondientes de la modernidad temprana, ni siquiera en la Magia naturalis de Della Porta o en el Ars magna lucis et umbrae de Athanasius Kircher ${ }^{16}$. Tanto más reveladora parece la reflexión sobre la magia en el mismo teatro del siglo de oro.

\section{El Teatro como cueva mágica}

Mientras que en el teatro del siglo XVIII la comedia de magia constituye un género aparte, el teatro barroco no excluye la magia de ningún género dramático ${ }^{17}$. Cuando en los escenarios del siglo XVII se practican hechicerías o se habla de ellas, aparecen generalmente en una perspectiva doble. En la perspectiva dramática el acto mágico es finalmente reducido a un artificio engañoso de origen humano o diabólico; en la perspectiva teatral es al contrario presentado y celebrado como un modelo del propio encanto del teatro ${ }^{18}$. Esto se puede ver con particular plasticidad en dos piezas escritas por dos autores más bien marginales del teatro barroco y dedicadas igualmente a una famosa cueva mágica que la leyenda popular ubica o bien a Toledo o bien a Salamanca: el entremés La cueva de Salamanca de Cervantes y la comedia homónima de Ruiz de Alarcón ${ }^{19}$. Ambas piezas presentan de una manera más o menos desilusionante un lugar apartado donde se enseña y se ejerce la magia, pero al mismo tiempo le confieren un prestigio nuevo caracterizándolo como una especie de laboratorio teatral. Si coinciden en esta revalorización profana de la cueva legendaria, cada una de las piezas idénticamente tituladas pone de relieve un aspecto distinto de la magia artificial del teatro.

${ }^{16}$ Acerca de estas obras influyentes, ver Zielinski, 2002, pp. 106-124, 155-168.

${ }^{17}$ Ver Arellano, 1996.

${ }^{18}$ Ver Caro Baroja, 1974, pp. 11-49. Acerca de la distinción sistemática entre una perspectiva dramática y una perspectiva teatral del espectador, ver Matzat, 1991.

${ }^{19}$ Sobre la recepción de esta antigua leyenda según la cual el diablo enseña el arte mágico en una cueva toledana o salmantina, ver García Blanco, 1951. El carácter secreto de la magia que se manifiesta en tales lugares es subrayado por Mauss y Hubert, 1985, p. 15 . 
El entremés cervantino de La cueva de Salamanca subraya el lado retórico e histriónico de esta magia sui generis. Si el protagonista, un estudiante ambulante llamado Carraolano, afirma haber aprendido la magia del mismo demonio en una cueva situada en Salamanca, lo hace para engañar tanto más efectivamente a un tal Pancracio en cuya casa quiere pernoctar. Con hechizos fingidos trata de impedir que su anfitrión prematuramente regresado a casa descubra a dos galanes que su esposa Leonarda y su criada han escondido en la carbonera. A este fin, Carraolano ofrece satisfacer la gran curiosidad de Pancracio con respecto a los secretos de la magia y le propone conjurar a dos diablos en forma humana. Logra ilusionarlo, ya que los galanes tiznados de carbón tienen aspecto de demonios, y el marido dos veces engañado se queda tan contento que quiere guardarlos en su casa para que le enseñen el arte de la hechicería. De tal modo, su hogar se transforma en una sucursal profana de la cueva de Salamanca, en una escuela de magia diabólica simulada con medios artificiosos. Estos medios provienen exclusivamente de la oratoria y del arte de representar. Por un lado, el hechizo embustero resulta de una simulación bastante elemental. Esto ya se anuncia en la escena primera cuando Leonarda finge desmayarse ante la partida de Pancracio y volver en sí gracias a un ensalmo pronunciado por él. Con aún mayor éxito la pareja cómica de los galanes escondidos en el desván simula salir directamente del infierno. Por otro lado, hace falta una persuasión elaborada para apoyar esta mascarada debida al azar. La magia de Carraolano se funda en su capacidad retórica que ya demostró en un cuento de bandoleros, declamado para que Leonarda lo hospedara en su casa. Cuando finge invocar a los diablos, empieza por un conjuro que saca del muy leído Laberinto de Fortuna de Juan de Mena, pero que adapta tan bien a la situación que parece proceder de un saber oculto; y termina por inventar la palabra «sacridiablo» por la cual metamorfosea a uno de los galanes, el sacristán de la aldea, en un diablo que le semeja asombrosamente. El mismo estudiante señala estas artimañas retóricas diciendo de la calidad de sus cómplices diabólicos: «más está en sabellos aconsejar que en conjurallos» ${ }^{20}$. La «ciencia» mágica que estudió en Salamanca se basa en la persuasión, no en el apremio; parece a aquella ciencia especial que Cervantes evoca en el Coloquio de los perros, a saber, «aquella ciencia que llaman tropelía, que hace parecer

${ }^{20}$ Cervantes, 2012, p. 115. Para el modelo del conjuro de Carraolano ver Mena, Laberinto de Fortuna, coplas 247-251. 
una cosa por otra» ${ }^{21}$. El secreto del protagonista que sólo el dueño de la casa no sabe descifrar reside en un juego de rol ingenioso, realizado como un truco de prestidigitación.

En la comedia La cueva de Salamanca de Alarcón, en cambio, la magia artificiosa del teatro resulta ante todo de la escenotécnica ${ }^{22}$. También en esta pieza la famosa cueva mágica se traslada a una casa particular, dado que el título se refiere a la morada tenebrosa del protagonista Enrico, un hechicero francés que se ha domiciliado en la ciudad universitaria para enseñar en cursos públicos su saber oculto. A diferencia del estudiante cervantino Enrico es sin embargo un mago verdadero: ha estudiado no solamente «eutropelías» (p. 147), es decir trucos de ilusionista, sino igualmente magia natural y sobre todo nigromancia, una ciencia que define ingeniosamente como el arte de apropiarse el poder de la naturaleza por imitación o por engaño: «a la naturaleza el poder quita / y engaña, almenos, quando no la imita» (p. 144). Gracias a estos conocimientos tiene un prestigio no menos grande que el marqués Enrique deVillena, el mago más famoso de la Edad Media, quien por lo tanto viene a verlo al principio de la comedia ${ }^{23}$. En parte con la ayuda de su colega ilustre, en parte por propio esfuerzo, Enrico ejecuta varios actos mágicos ante los ojos de los asistentes. Algunos de estos actos sirven para escarmentar al estudiante incrédulo Zamudio, una suerte de segundo Carraolano. A este fin, el protagonista hace aparecer y desaparecer una comida amorosa: apenas materializado, el tocino se transforma en carbón, mientras que la querida conjurada se metamorfosea en un león. En otra ocasión, enfrenta a Zamudio con la cabeza de un decapitado que de repente se pone a hablar y termina por estallar. No obstante, la mayor parte de los hechizos sirven para proteger a un amigo mujeriego llamado Don Diego de la persecución por el poder judicial. Cuando este individuo trata de esconderse en la casa de Enrico, éste lo hace desaparecer en una habitación sin ventanas; más tarde, lo hace atravesar los muros de la cárcel, después de pegar fuego desde lejos a ciertos documentos incri-

${ }^{21}$ Cervantes, 2001, p. 592. Acerca del término tropelía o eutropelía, que además del ‘juego de manos' designa también el 'juego' en general, ver Wardropper, 1982.

${ }^{22}$ Texto y paginación conforme a Ruiz de Alarcón, 1990. La importancia de la magia en las comedias alarconianas es destacada, aunque no vinculada a la magia artificiosa, por Espantoso Foley, 1972.

${ }^{23}$ Acerca de este personaje llamado «el Nigromante» ver Garrosa Resina, 1987, pp. $338-345$. 
minatorios; a medio camino, hace entrar a Don Diego en el aposento de su dama, transformándolo provisionalmente en una estatua de tamaño real. Al final, sin embargo, la magia tan bien demostrada del protagonista es desenmascarada y refutada como un mero artificio del diablo. En una disputación pública un teólogo convence a Enrico de que bajo el disfraz de la magia natural y de la magia artificiosa se esconde casi siempre la magia diabólica, es decir, un hechizo sobrehumano; le explica que incluso el marqués de Villena, recién fallecido, no pudo engañar al diablo sino después de renegarlo definitivamente. Es probable que tales argumentos provengan del tratado de Martín del Río. Pero en la comedia de Alarcón tiene un sentido más complejo lo que en la disputación se dice de la tercera variante de la magia:

la artificiosa consiste, en la industria, o ligereza

Del ingenio, o de las manos, obrando cosas con ellas, que engañen algun sentido, y que imposibles parezcan (p. 169)

Es preciso justamente un tal engaño de los sentidos para poner las hechicerías de Enrico ante los ojos del público. Como lo indican las acotaciones sumamente detalladas de la comedia, Alarcón toca todos los registros de la escenotécnica a este efecto. El tocino y la querida de Zamudio desaparecen en el foso, mientras que el león sale de una peña hueca (pp. 154-155); la cabeza cortada contiene una cerbatana y un barreno (p. 156); Don Diego se aleja en una nube mecánica o sale de un cajón con dos puertas en cuyo otro lado está una estatua de su tamaño (pp. 142,163-164). Por supuesto, el espectador no tiene que ver todos estos huecos y escotillones si quiere disfrutar de la magia del teatro. No obstante, puede al menos conjeturarlos cuando Enrico explica a los perseguidores de su amigo desaparecido:

\footnotetext{
Toda la casa es un palmo, sin alacena, tabique, bóveda, cueva o sobrado: no hay colgaduras, que puedan encubrir portillos falsos (p. 143)
} 
Sin duda, esto es cierto con respecto a la situación representada; en la representación teatral, sin embargo, coluden justamente todas las máquinas evocadas por negación. Así, se alude de un modo discreto a la tramoya invisible. Para que la casa de Enrico pueda asemejarse a la cueva de Salamanca, se necesitan varias «cuevas» detrás, debajo y por encima del tablado. Todo el resto resulta de «eutropelías» muy especiales, a saber, de las maniobras de los tramoyistas.

En ambas piezas es por lo tanto el mismo teatro que se presenta como la verdadera cueva mágica, aunque a luces muy distintas. El entremés de Cervantes muestra una magia teatral que se basa únicamente en la actuación del comediante y por eso puede prescindir de recursos materiales. Es de ella que habla un actor del Barroco cuando califica de «halagos e industrias [...] la magia que profes[a]» ${ }^{24}$. Esta hechicería elemental proviene del carro de Tespis y predomina aún en el corral de comedias a principios del siglo XVII. La comedia de Alarcón, en cambio, presenta una magia teatral basada en la tramoya que será perfeccionada en los escenarios palaciegos a mediados del siglo ${ }^{25}$. El efecto no menos grande, quizás aun mayor de esta segunda variante se puede desprender del hecho de que el tramoyista ingenioso Cosme Lotti fue apodado «El Hechicero» en su tiempo. De hecho, las dos formas teatrales de la magia artificiosa no se exluyen de ninguna manera, sino que pueden juntarse en una misma pieza. Lo prueba y lo reflexiona al mismo tiempo $\mathrm{La}$ dama duende de Calderón ${ }^{26}$.

\section{UN DUENDE INGENIADO Y SIMULADO}

La comedia de capa y espada más conocida de Calderón, escrita en 1629 , señala ya por su título aliterado que se refiere a la discusión contemporánea sobre supersticiones y hechicerías ${ }^{27}$. Como es sabido, la pieza trata de un trasgo que parece habitar un cuarto apartado de la casa de la familia Toledo, domiciliada en Madrid. Don Manuel, un caballero hospedado allí por los hermanos Don Juan y Don Luis, recibe visitas

${ }^{24}$ Citado por Rodríguez Cuadros, 1998, p. 20.

${ }^{25}$ Sobre esta evolución, ver por ejemplo Cohen, 1985, pp. 264-281.

${ }^{26}$ Para un tratamiento más amplio del papel de la magia en las comedias de Calderón, ver Nitsch, 2005; el presente artículo es un extracto revisado de este estudio.

${ }^{27}$ Todas las citas siguientes se refieren a la edición excelente de Fausta Antonucci, 1999. 
nocturnas de un duende que trastorna su equipaje, sustrae objetos de valor y deja cartas desconcertantes. El huésped no tarda en sospechar que se trata en realidad de una "dama duende», es decir de una admiradora secreta, pero tarda mucho en reconocer que tiene trato con Doña Ángela, la hermana viuda y bien guardada de sus anfitriones, con quien ya ha tropezado al llegar a Madrid. Cuando la «dama duende» deja caer la máscara y confiesa amarle, se arma un conflicto de honor entre Don Manuel y Don Luis, pero éste termina por consentir a las segundas bodas de su hermana. Hasta este desenlace convencional reina sin embargo la confusión general que - como en muchas comedias de Tirso de Molina - se origina en el enredo de la protagonista ${ }^{28}$. La innovación de Calderón frente al modelo tirsiano consiste en vincular este juego de rol con maniobras técnicas muy sugestivas, de suerte que hasta un escéptico emperdenido sucumbe momentáneamente a su encanto irresistible.

El juego simulador jugado por la viuda no tendría tanto éxito sin un artificio escenotécnico original. Este artificio consiste en una "alacena de vidrios» (v. 359) instalada en el cuarto de Don Manuel que se puede utilizar como una puerta giratoria dando al patio, de modo que resulta posible entrar y salir sin ser percibido ${ }^{29}$. El uso de este mueble al parecer bien clavado a la manera de una secreta entrada traserase debe al ingenio mecánico de la criada Isabel. Al limpiar la casa, Isabel desclavó por descuido el soporte del mueble y descubrió así que se trataba de una alacena «portátil» (v. 590); además, logró transformar el armario en puerta practicable fijando los clavos sueltos «en falso» (v. 613). Solamente gracias a esta invención las mujeres pueden aparecer y desaparecer como duendes en el cuarto de huéspedes; de tal modo, la puerta giratoria creada por azar llega a ser la piedra angular de la acción dramática ${ }^{30}$. «Alacena me fecit» (v. 892), observa Isabel con mucha razón tras cambiar por carbón el dinero de Cosme, el criado de Don Manuel, tal como lo hiciera un trasgo según la superstición popular. Y no en balde su invención ingeniosamente simple es comparada con el famoso huevo de Colón:

${ }^{28}$ Esta particularidad de la pieza, poco típica de las comedias calderonianas de capa y espada, es subrayada por Matzat, 1986, p. 67. Acerca del enredo simulador en las comedias tirsianas, ver Nitsch, 2000, en particular pp. 141-155, y 2001.

${ }^{29}$ Acerca del del espacio representado en la comedia, verVitse, 1996.

${ }^{30}$ Acerca de la importancia dramatúrgica de la alacena, ver Arellano, 2006. 


\author{
¿Ahora sabes \\ lo del huevo de Juanelo? \\ Que los ingenios más grandes \\ trabajaron en hacer \\ que en un bufete de jaspe \\ se tuviese en pie, y Juanelo \\ con sólo llegar y darle \\ un golpecillo, le tuvo. \\ Las grandes dificultades, \\ hasta saberse lo son, \\ que sabido, todo es fácil (vv. 1256-1266)
}

La invención proverbial no se atribuye aquí al descubridor de América, sino al ingeniero Juanelo Turriano quien bajo el reino de Carlos I y Felipe II construyó relojes, autómatas y aparatos hidráulicos, en particular el célebre "artificio de Juanelo» que elevaba el agua del Tajo al alcázar de Toledo ${ }^{31}$. El cuentecillo sugiere, pues, que también en la casa de los Toledo se puede admirar un mecanismo maravilloso; la ingeniería de la criada produce apariciones dignas de la cueva mágica de Toledo o de Salamanca. Los huéspedes subrayan por su parte el vínculo entre la técnica y la magia. Poco antes de descubrir el encantamiento de su dinero, Cosme maldice la capital española porque ha caído en la zanja de una fuente: insulta al ingeniero responsable de la canalización urbana llamándole un "traidor quien da paso a su enemigo» (v. 710), es decir, quien abre vías al agua, un líquido tradicionalmente aborrecido por el gracioso; y se figura al mismo tiempo que los canales de agua se metamorfosean en canales de vino, como para compensar este agravio intolerable. Así, el criado alude a la ingeniería como a una especie de magia negra que hay que rechazar por hechizos contrarios. Con respecto a las hechicerías no menos técnicas del duende, empero, Cosme está todavía sin defensa ninguna.

A partir de la segunda jornada el juego de rol inquietante se independiza del mecanismo que lo ha hecho posible en la primera jornada. El enredo urdido por la criada gana en dinamismo lúdico en la medida que la misma dama toma la iniciativa.Ya en la ocasión de la primera visita secreta al cuarto del huésped Doña Ángela ha entrado en el juego de

${ }^{31}$ Sobre los inventos de Turriano, admirados por muchos escritores del Siglo de Oro, ver García Tapia y Carrillo Castillo, 2002, pp. 27-56. 
Isabel, escribiendo una carta anónima a Don Manuel; así, tras presenciar de incógnito una fiesta en el «teatro» (v. 397) de la plaza Palacio y admirar la invención genial de la puerta-alacena, ha empezado a desempeñar el papel de la «dama duende» en la compañía de la criada trasguera para ponerse en contacto con el inquilino nuevo. Al entrar de nuevo en su cuarto vacío, este juego secreto se transforma sin querer en un espectáculo visto por otros, ya que Don Manuel y Cosme entran inesperadamente y sorprenden en flagrante a la visitante iluminada por una vela.Aun más visible, por no decir en iluminación teatral, se presenta al huésped cuando éste le devuelve una visita en su propio cuarto adonde ha sido guiado por caminos sinuosos y en plena oscuridad. En la tercera jornada, pues, Doña Ángela ya no necesita la alacena para continuar su juego; le basta disfrazar su aposento de lugar apartado — tan apartado como la cueva legendaria. Últimamente, su juego voluntario y perfectamente visible se hace bastante temerario. Mientras que al principio espera aún prudentemente sus oportunidades, al fin comete dos «descuidos» consecutivos: el primero ocurre en el marco del juego, cuando revela involuntariamente su condición de gran señora (v. 2418); el segundo (v. 2617), en cambio, se produce en realidad, porque la pomposa recepción organizada para Don Manuel, de la cual participa también su amiga Doña Beatriz, adorada tanto por Don Juan como por Don Luis, suscita sin falta la atención de los hermanos y por lo tanto un duelo de honor, interrumpido poco antes de ponerse sangriento.

Así, Doña Ángela termina por asemejarse a las protagonistas audaces de Tirso o bien a la actriz contemporánea Amarilis alias María de Córdoba cuyas actuaciones arriesgadas, semejantes a las de un «volatín» (v. 33), son celebradas al principio de la comedia. El enredo inspirado por la alacena "portátil» y literalmente maquinado por la criada se ha vuelto un juego de simulación apenas controlable ${ }^{32}$. No obstante, el origen escenotécnico de este juego permanece siempre patente. Por un lado, la intriga femenina es designada hasta el fin con la palabra «tramoya» (vv. 2246, 2805) que no pierde nunca el sentido literal de 'máquina de teatro', tanto más presente cuanto que la protagonista alaba discretamente a las «mujeres tramoyeras» (v. 517) poco antes de indagar

${ }^{32}$ Un desarrollo semejante marca los acontecimientos mágicos en la fiesta mitológica El mayor encanto, amor: mientras que al principio la encantadora Circe efectúa aún varios maleficios, a continuación se fía únicamente de un juego de simulación para enamorar a Ulises. 
las posibilidades abiertas por la puerta giratoria. Mientras que Lope de Vega afirma de vez en cuando que «tramoya» y "poesía», escenotécnica y arte de representar se excluyen mutuamente, Calderón junta los supuestos polos contrarios en un título de honor equívoco ${ }^{33}$. Por otro lado, Doña Ángela se refiere aún a ciertas técnicas de ilusión óptica cuando ya puede prescindir del invento de la alacena. Durante la curiosa representación en su aposento compara su propia apariencia a un cuadro ambiguo "que una forma a una luz tiene / y a otra luz tiene otra forma» (vv. 2385-2386). Así se puede definir la anamorfosis que es una de las formas barrocas más elaboradas de la magia artificiosa ${ }^{34}$. De tal modo, hasta en el apogeo de su juego de rol independizado la protagonista rinde homenaje a un artificio destinado a engañar los sentidos.

La metáfora de la anamorfosis ilustra al mismo tiempo la muy distinta percepción de la «dama duende» por parte de los dos huéspedes de la casa. Los debates que sostienen acerca de ella sugieren que sólo Cosme sucumbe al encanto de las visitas misteriosas, mientras que Don Manuel las afrenta con escepticismo y sangre fría. El criado cree tener realmente trato con un trasgo tal como lo imagina la superstición popular, pero también el tratado de Torquemada ${ }^{35}$. Se explica las transformaciones y apariciones en el cuarto de su amo por la obra sobrenatural de un demonio menor que no trata de tentar a sus víctimas, pero que no obstante intenta asustarlas y perjudicarlas materialmente. Para Cosme se trata, pues, de magia diabólica, y conforme a eso muestra reacciones muy fuertes. Bien es verdad que no evacúa su intestino, como lo hacen otros graciosos en situaciones parecidas, pero sí su memoria, de suerte que olvida traer consigo papeles importantes de su amo cuando lo acompaña a la corte. Don Manuel, por el contrario, rechaza categóricamente toda explicación sobrenatural de los sucesos extraños. Desde el punto de vista de su fe racional no pueden existir ni «duendes» ni siquiera «mágicos», «nigromantes o "encantadoras», porque el diablo es "sin poder notorio" (vv. 1079-1088). No concede sino fuentes profanas de lo maravilloso, como por ejemplo «ingenio y arte» (v. 1071) o «mano y cautela» (v.

${ }^{33}$ Sobre la actitud crítica de Lope frente a la comedia de tramoya, ver Asensio, 1981.

${ }^{34}$ Ver Baltrušaitis, 1984; ver Nelson, 2002.

35 Ver Torquemada, 1982, pp. 298-302. Sobre las supersticiones populares vinculados al duende y su recepción literaria, ver Caro Baroja, 1984; acerca de su presencia en la comedia calderoniana, ver Cazés Gryj, 2013, pp. 65-68. 
1409). Dicho de otra manera, interpreta la obra del duende como un efecto de magia artificial.

Aunque Don Manuel acierta con su actitud escéptica, esta forma de la magia surte sin embargo un efecto tan fuerte que sufre un momento de confusión notable. En el primer encuentro con la «dama duende» se le enfrían los pies y se queda sin respiración, mientras que tiene «el cabello erizado» (v. 2073). A pesar de que no tarda en romper este «encanto» (v. 2079) sin encanto, por un instante éste lo tiene sujeto hasta los tuétanos. Ni siquiera su capacidad de penetrar las maniobras ingeniosas que están detrás parece protegerlo de la violencia de la magia escénica que Doña Ángela de Toledo saca de la invención de su criada. Con respecto a esta reacción momentánea, Don Manuel imita sin querer a Don Quijote a cuya creencia en la magia alude en su carta de respuesta a la dama misteriosa ${ }^{36}$. Al menos instantáneamente el «encanto» (p. 53) burlado en esta página llena de ironía se manifiesta de hecho en el cuerpo del «caballero de la dama duende» (p. 54).

${ }^{36}$ La semejanza latente entre los dos personajes es destacada por Parker, 1988, pp. 143-152. 


\section{BiBLIOGRAFÍA}

Arellano, Ignacio, «Magos y prodigios en el escenario de Siglo de Oro», en En torno al teatro del Siglo de Oro, ed. José Berbel et al., Almería, Instituto de Estudios Almerienses, 1996, pp. 13-35.

Arellano, Ignacio, "La dama duende y sus notables casos» [2001], en El escenario cósmico. Estudios sobre la comedia de Calderón, Madrid / Frankfurt, Iberoamericana / Vervuert, 2006, pp. 187-201.

Asensio, Eugenio, «Tramoya contra poesía. Lope atacado y triunfante (16171622)», en Teoría y realidad en el teatro español del siglo XVII. La influencia italiana, ed. Francisco Ramos Ortega, Roma, Instituto Español de Cultura y Literatura, 1981, pp. 257-270.

Baltrušaitis, Jurgis, Anamorphoses ou Thaumaturgus opticus, Paris, Flammarion, 1984 [1955].

Calderón de la Barca, Pedro, La dama duende, ed. Fausta Antonucci, Barcelona, Crítica, 1999 (Biblioteca Clásica, 69).

Caro Baroja, Julio, «Los duendes en la literatura clásica española» [1944], en Del viejo folklore castellano, Valladolid, Ámbito, 1984, pp. 133-172.

Caro Baroja, Julio, Teatro popular y magia, Madrid, Revista de Occidente, 1974 (Biblioteca de ciencias históricas 5).

Cazés Gryj, Dann, "Construcción de la mentira sobrenatural en La dama duende y El galán fantasma», Anuario Calderoniano, 6, 2013, pp. 61-73.

Cervantes, Miguel de, Novelas ejemplares, ed. Jorge García López, Barcelona, Crítica, 2001 (Biblioteca clásica, 49).

Cervantes, Miguel de, Entremeses, ed. Alfredo Baras Escolá, Barcelona, Galaxía Gutenberg, 2012 (Biblioteca clásica de la Real Academia Española, 45).

Ciruelo, Pedro, Reprobación de las supersticiones y hechicerías [1538], ed. Francisco Tolsada, Madrid, 1952 (Joyas bibliográficas, 7).

Cohen, Walter, Drama of a nation. Public theater in Renaissance England and Spain, Ithaca / London, Cornell University Press, 1985.

Del Río, Martín, Disquisitiones magicae, Leuven, 1599/1600.

Espantoso Foley, Augusta, Occult arts and doctrine in the theater of Juan Ruiz de Alarcón, Genève, Droz, 1972 (Travaux d'humanisme et renaissance, 222).

Frazer, James G., The golden bough. A study in magic and religion, London, Macmillan, 1911, vol. 1.

García Blanco, Miguel, «El tema de la Cueva de Salamanca y el entremés cervantino de este mismo título», Anales Cervantinos, 1, 1951, pp. 73-109.

García SANTO-Tomás, Enrique, La musa refractada. Literatura y óptica en la España del Barroco, Madrid / Frankfurt, Iberoamericana / Vervuert, 2014 (Tiempo emulado, 35).

García Tapia, Nicolás y Jesús Carrillo Castillo, Tecnología e imperio. Ingenios y leyendas del Siglo de Oro, Madrid, Nivola, 2002. 
Garrosa Resina, Antonio, Magia y superstición en la literatura castellana medieval, Valladolid, Universidad de Valladolid, 1987 (Biblioteca de Castilla y León, Literatura 1).

Grafton, Anthony, Magic and technology in early modern Europe, Washington D. C., Smithsonian Institution Libraries, 2002 (Dibner Library Lecture).

Kemp, Martin, The science of art, New Haven / London, Yale University Press, 1990.

LÉvi-Strauss, Claude, «Le sorcier et sa magie» [1949], en Anthropologie structurale, Paris, Plon, 1974, pp. 191-212.

Malinowski, Bronislaw, «Magic, science and religion» [1925], en Magic, science and religion and other essays, London, Souvenir, 1974, pp. 13-92.

Matzat, Wolfgang, "Die ausweglose Komödie. Ehrenkodex und Situationskomik in Calderóns comedia de capa y espada», Romanische Forschungen, 98, 1986, pp. 58-80.

Matzat, Wolfgang, «La prueba: una estructura básica del teatro calderoniano», en Hacia Calderón. Noveno Coloquio Anglogermano Liverpool 1990, ed. Hans Flasche, Stuttgart, Franz Steiner, 1991, pp. 113-122.

Mauss, Marcel y Henri Hubert, «Esquisse d'une théorie générale de la magie» [1902], en Marcel Mauss, Sociologie et anthropologie, Paris, PUF, 1985 (Quadrige, 58), pp. 1-141.

Nelson, Bradley J., "The marriage of art and honor: anamorphosis and control in Calderón's La dama duende», Bulletin of the Comediantes, 54/2, 2002, pp. 407-441.

Nitsch, Wolfram, Barocktheater als Spielraum. Studien zu Lope de Vega und Tirso de Molina, Tübingen, Narr, 2000 (Romanica Monacensia, 57).

Nitsch, Wolfram, «El teatro barroco como juego: La villana de Vallecas de Tirso de Molina», en Actas del V Congreso de la Asociación Internacional Siglo de Oro, ed. Christoph Strosetzki, Madrid / Frankfurt, Iberoamericana / Vervuert, 2001, pp. 934-940.

Niтsch, Wolfram, "Theater der Magie / Magie des Theaters. Spuk und Zauberei im Theater Calderóns», en Der Prozeß der Imagination. Magie und Empirie in der spanischen Literatur der frühen Neuzeit, ed. Wolfgang Matzat y Gerhard Penzkofer, Tübingen, Niemeyer, 2005 (Beihefte zur Iberoromania, 21), pp. 307-321.

Parker, Alexander A., The mind and art of Calderón. Essays on the "comedias", Cambridge, Cambridge University Press, 1988.

Rodríguez Cuadros, Evangelina, La técnica del actor español en el Barroco. Hipótesis y documentos, Madrid, Castalia, 1998 (Literatura y sociedad).

Ruiz de Alarcón, Juan, La cueva de Salamanca, en Obras completas, ed. Alva V. Ebersole,Valencia, Álbatros, 1990, vol. 1, pp. 137-171.

Тамвіан, Stanley J., Magic, science, religion, and the scope of rationality, Cambridge, Cambridge University Press, 1990. 
Todorov, Tzvetan, «Le discours de la magie», L’Homme, 13, 1973, pp. 38-65.

Torquemada, Antonio de, Jardín de flores curiosas [1570], ed. Giovanni Allegra, Madrid, Castalia, 1982 (Clásicos Castalia, 125).

ViTse, Marc, «Sobre los espacios en La dama duende: El cuarto de don Manuel» (1985), en De hombres y laberintos. Estudios sobre el teatro de Calderón, ed. Ignacio Arellano y Blanca Oteiza, Madrid, Rilce, 1996, pp. 336-356.

Wardropper, Bruce W., "La eutrapelia en las Novelas ejemplares de Cervantes», en Actas del VII Congreso de la Asociación Internacional de Hispanistas, ed. Giuseppe Bellini, Roma, Bulzoni, 1982, vol. 1, pp. 153-169.

Wittgenstein, Ludwig, «Bemerkungen über Frazers Golden Bough» [1931], en Vortrag über Ethik und andere kleine Schriften, ed. Joachim Schulte, Frankfurt, Suhrkamp, 1989, pp. 29-46.

Yates, Frances A., Giordano Bruno and the hermetic tradition, London, Routledge, 1964.

Zielinski, Siegfried, Archäologie der Medien. Zur Tiefenzeit des technischen Hörens und Sehens, Reinbek, Rowohlt, 2002. 